\title{
Neurotoxicidade do cloreto de amônio 2\% sobre os nervos digitais palmares em pôneis
}

Stefano Leite Dau ${ }^{[a]}$, Marcos da Silva Azevedo[b], Flávio De La Côrte ${ }^{[a]}$, Karin Érica Brass ${ }^{[a]}$, Gabriele Biavaschi Silva ${ }^{[a]}$, Camila Cantarelli[a], Renata Dalcol Mazaro ${ }^{[a]}$, Rafael Almeida Fighera ${ }^{[a]}$

\footnotetext{
[a] Universidade Federal de Santa Maria (UFSM), Santa Maria, RS, Brasil

[b] Universidade Federal de Santa Catarina (UFSC), Curitibanos, SC, Brasil
}

*Autor correspondente

e-mail: stefanodau@hotmail.com

\section{Resumo}

A administração perineural de drogas anestésicas é rotineira na medicina de equinos para bloqueios neurais temporários durante procedimentos cirúrgicos em estação, para identificação da origem da dor em exames de claudicação e para fins terapêuticos como o controle da dor pós-operatória. Os neurolíticos são drogas que causam uma degeneração neural reversível utilizadas, em associação ou não com outras terapias, para o controle da dor crônica. Contudo, a duração do efeito desses compostos depende do local de deposição e da severidade da lesão nervosa causada. 0 objetivo deste estudo foi determinar e descrever a neurotoxicidade do cloreto de amônio a 2\% (CA2\%), após a administração perineural nos nervos digitais palmares (NDPs) em seis pôneis. Utilizou-se aleatoriamente os ramos lateral e medial dos NDPs de ambos os membros torácicos dos animais, sendo três ramos tratados com três mililitros de CA2\% ( $\mathrm{n}=18$ ) e um ramo com três mililitros de solução salina $0,9 \%(\mathrm{SS})(\mathrm{n}=6)$. A região palmar da quartela foi preparada assepticamente para a realização das injeções perineurais após tricotomia. A distância do local de inserção da agulha até a banda coronária foi mensurada para posterior orientação na coleta de fragmentos dos NDPs. Utilizou-se a termografia para documentar a temperatura superficial da pele (TSP) na região palmar da quartela em cinco pontos verticais equidistantes sobre cada ramo antes, uma, três, seis, 12 e 24 horas após as injeções para avaliar a resposta inflamatória local. Os fragmentos dos NPDs (1,5cm) foram coletados cinco, 12, 19, 35, 47 e 62 dias após os tratamentos por meio de neurectomia pela técnica de guilhotina, com os animais sob anestesia geral inalatória, sendo alocado um animal para cada momento. As amostras foram fixadas em solução de formol tamponado $10 \%$, processadas rotineiramente para histopatologia e coradas pela hematoxilina-eosina. Dois avaliadores cegos aos tratamentos classificaram as alterações histopatológicas de acordo com o grau de degeneração nervosa em: ausente, leve, moderada ou severa. Não observou-se 
diferença entre os tratamentos $(\mathrm{P}>0,05)$ quanto à TSP nas primeiras 24 horas, porém se constatou um aumento médio de $1,8^{\circ} \mathrm{C}\left( \pm 0,35^{\circ} \mathrm{C}\right)$ e $2,43^{\circ} \mathrm{C}\left( \pm 0,7^{\circ} \mathrm{C}\right)$ após injeção de SS e CA2\%, respectivamente, neste período. As alterações histológicas identificadas incluíram graus variáveis de substituição multifocal da parede axonal por material homogêneo, marcadamente eosinofílico e de formato elipsóide, caracterizando a presença de esferóides axonais, indicando degeneração Waleriana. Em alguns locais, parte dos fascículos foram substituídos por tecido conjuntivo fibroso. Essas lesões foram observadas do quinto ao $62^{\circ}$ dia em $78 \%$ ( $\mathrm{n}=14 / 18$ ) dos ramos tratados com CA2\%, sendo que lesões leves, moderadas e severas foram identificadas em 36\%, 28\% e 36\% destas amostras, respectivamente. Observou-se também alterações leves e moderadas em $17 \%$ e $50 \%$ dos nervos tratados com SS, o que pode ser atribuído à ruptura de fibras nervosas durante a inserção da agulha ou caso tenha ocorrido aplicação intraneural. O posicionamento preciso da agulha, dentro ou fora do feixe neurovascular, poderia explicar a variação das lesões após a utilização do CA2\%, visto que a injeção perineural está associada a lesões nervosas intermediárias e a injeção intraneural com lesões mais severas. Os resultados do presente estudo indicam que o CA2\% produz lesões nervosas de diferentes graus do quinto ao $62^{\circ}$ dia após injeção perineural dos NDPs, podendo o efeito clínico deste produto estar relacionado com a severidade da lesão nervosa gerada. Assim, salienta-se a necessidade de uma técnica acurada para uma correta deposição do fármaco no feixe neurovascular.

Palavras-chave: Claudicação crônica. Neurectomia. Neurólise.

Agradecimentos: à FATEC/UFSM (projeto 5.03.0025), à FAPERGS/CAPES e à empresa Vetnil Indústria e Comércio de Produtos Veterinários Ltda pelo apoio financeiro. 